\title{
TRICOPTER VIBRATION ANALYSIS
}

\section{Vladimír POPARDOVSKÝ, Marek FERENČÁK, Tomáš KRIŠ, Miroslav TOMAŠTíK, Lukáš NOVOTNÝ}

Armed Forces Academy of General M. R. Štefánik, Demänovská cesta 393, Liptovský Mikuláš 031 01, Slovakia E-mail: vladimir.popardovsky@aos.sk, marek.ferencak@aos.sk, tomas.kris@aos.sk, miroslav.tomastik@aos.sk, lukas.novotny@aos.sk

\section{Abstract}

Unmanned Aerial Vehicle (UAV) is exposed to various types of stress during flight. One of the most significant negative influences is the vibrations produced by the rotating parts. If we assume a UAV of the multicopter type, it is a stress of the whole structure by vibrations produced by propulsion units, which are placed on symmetrically distributed arms. The propulsion unit consists of an electric-propeller assembly, with the propeller being the largest source of vibration. This is due to the uneven distribution of the mass with respect to its axis of rotation. In addition to the propeller, the rotating part is also the electric motor itself, although the electric motor contributes much less to the total vibrations than the propeller. For this reason, it is necessary to balance the propeller first statically and then dynamically balance the entire drive unit (engine + propeller). Our work is focused on vibration diagnostics of an experimental tricopter in order to optimize the power units - to produce the smallest possible vibrations.

Keywords: multicopter, vibrations, Fourier transform, vibration analysis, MATLAB

\section{INTRODUCTION}

The aim of our work was to design an experiment that would allow the implementation of vibration diagnostics [1][2][3][4] of the UAV type multicopter (in our case it was a tricopter) during its flight (in the selected flight mode). Subsequent processing of the measured data should allow the setting of the drive units so that the vibrations produced by these units are minimal.

Our experiment consisted of the following activities:

- $\quad$ static balancing of propeller;

- dynamic balancing of power units (engine + propeller).

Dynamic balancing made it possible to find the position of the propeller for each power unit, which then produced the least vibrations.

\section{OUR EXPERIMENTAL MULTICOPTER}

For experiment was used by us manufactured tricopter [5] in a T-configuration (so called $\mathrm{T}$ copter). It is a system with three rotors placed in $\mathrm{Y}$ or $\mathrm{T}$ shape.

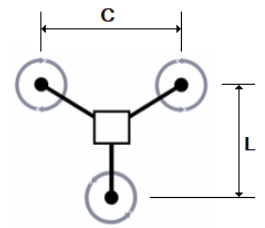

Fig. 1. Schema of tricopter
Position of the front pair of rotors is fixed and part of the arm of the rear rotor is rotatable around its longitudinal axis, thereby allowing the rotor to tilt laterally. The tricopter is controlled by changing velocity of the rotations of the rotors and tilting the rear rotor. Flight is only possible with all rotors working [6].

Drive unit of our T-copter consists of electric engine and propeller. Hextronik electric engines, type DT-750 (Kv=750rpm) were used for powering full-carbon propellers with parameters $12 \times 3.8$ inch. T-copter was powered by three identical drive units. Power source consist from two LiPol battery in parallel arrangement.

Dimensions of T-copter:

- Carrier arms span (C): 800 mm;

- $\quad$ Length (L): $780 \mathrm{~mm}$;

- Flying weight: $1570 \mathrm{~g}$.

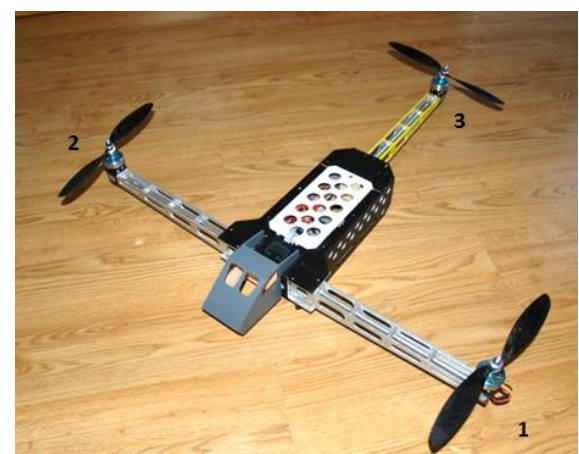

Fig. 2. Our T-copter with drive units number marking 


\section{STATIC BALANCING OF PROPELLER}

Static balancing [7] of the propeller is a process whose purpose is to adjust the originally uneven distribution of the propeller mass - we say that the propeller is statically unbalanced. The practical manifestation of this condition is different mass of the propeller blades. The remedy is to add the missing weight (eg spraying paint on the blade), or to remove the excess weight (sanding the blade) so that we achieve its even (symmetrical) distribution with respect to the axis of rotation. Fortunately, the difference in leaf weight is usually minimal.

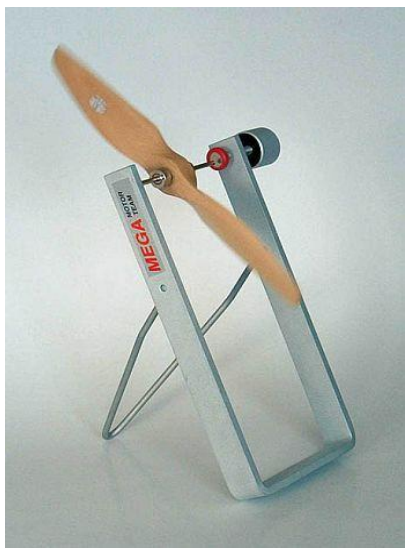

Fig. 3. Magnetic balancer

The device for checking the balance of the propeller is e.g. magnetic balancer in which the free rotation of the propeller in the supporting magnetic field is allowed. The imbalance is manifested by the "fall" of the heavier blade (by turning the propeller to the position of the heavier blade to the ground) due to the greater gravitational force acting on such a blade.

\section{DYNAMIC BALANCING OF THE DRIVE UNIT}

Dynamic balancing [7][8] of the propulsion unit is a process which results in the minimization of vibrations produced by the operation of the submersible unit. One of the possibilities how to dynamically balance the rotating system is the following experimental procedure - by changing the distribution of the mass of rotating parts with respect to the axis of rotation, to monitor the level of vibrations. And consequently, ensure a distribution of the mass of the rotating parts that produces minimal vibrations.

In our case, the change in the mass distribution of the rotating parts was ensured by changing the position of the propeller relative to the arm-motor reference line. A mark was made on the rotating casing of the engine to ensure that before turning the propeller to the new position, the engine was always brought to the same starting position.

For experimental measurements, we used four propeller positions - the starting position of the propeller was selected with respect to the longitudinal axis of the carrier arm, from $0^{\circ}$ to the $135^{\circ}$ with a step of $45^{\circ}$, as is shown in Fig. 4. Positions $180^{\circ}-360^{\circ}$ was not measured, because $180^{\circ}=0^{\circ}, 225^{\circ}=45^{\circ}, 270^{\circ}=90^{\circ}, 315^{\circ}=135^{\circ}$, $360^{\circ}=0^{\circ}$. These positions are identical under the presumption, that propellers are statically balanced.

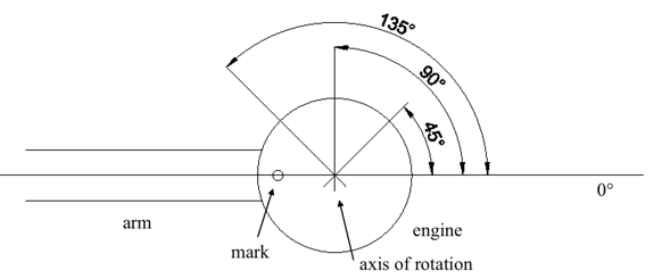

Fig. 4. Determining the position of the propeller relative to the arm-engine reference line

\section{EXPERIMENT DESCRIPTION}

The essence of the experiment is to measure the vibrations in the center of gravity of the tricopter, for all combinations of positions of all three propellers. The aim was to find a combination of propeller positions in which the lowest level of vibration was measured at the center of gravity.

The principle of measurement [9][10] is shown in Fig. 5. In order to eliminate the effect of wind, the measurement was performed indoors. The Tcopter was put into flight mode by a hovercraft - 2 $\mathrm{m}$ above the ground platform. In this state, vibration acceleration measurements were performed in all three axes by accelerometers. After landing, the propellers were adjusted to new positions and another flight and new measurements were performed.

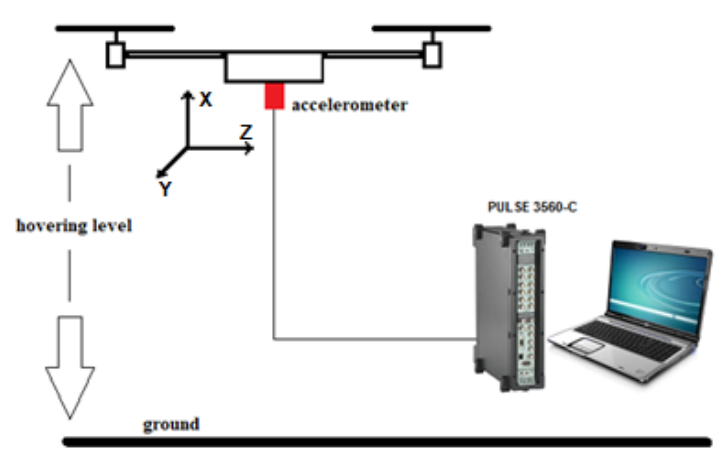

Fig. 5. Experiment setup

The 3-axis piezoelectric accelerometer 4524-B of the Bruel\&Kjaer PULSE 3560-C vibrodiagnostic system was placed in the center of gravity of the Tcopter (on the lower part of the fuselage). The accelerometer used is capable of measuring accelerations in the range of $+/-50 \mathrm{~g}$, with a frequency range from $2 \mathrm{~Hz}$ to $5.5 \mathrm{kHz}$. This sensor has built-in electronics and belongs to the low 
impedance class - which allows measurement with long wires.

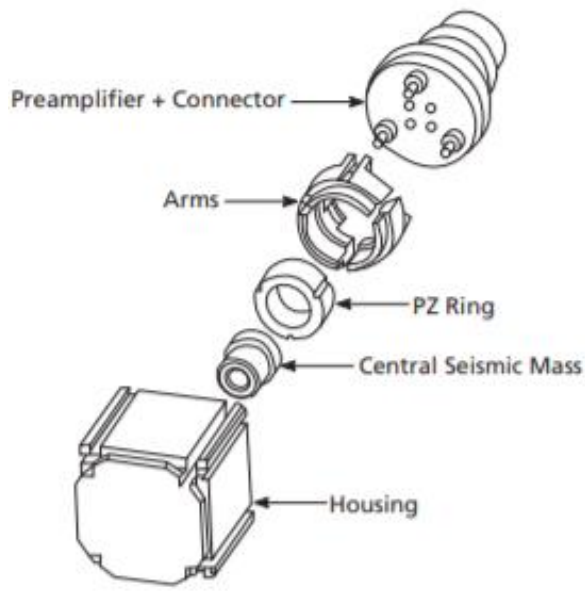

Fig. 6. Exploded view of 4524-B sensor

The PULSE is a versatile task-oriented system for noise and vibration analysis. Type $3560-\mathrm{C}$ is a portable data acquisition system made for outdoor use.

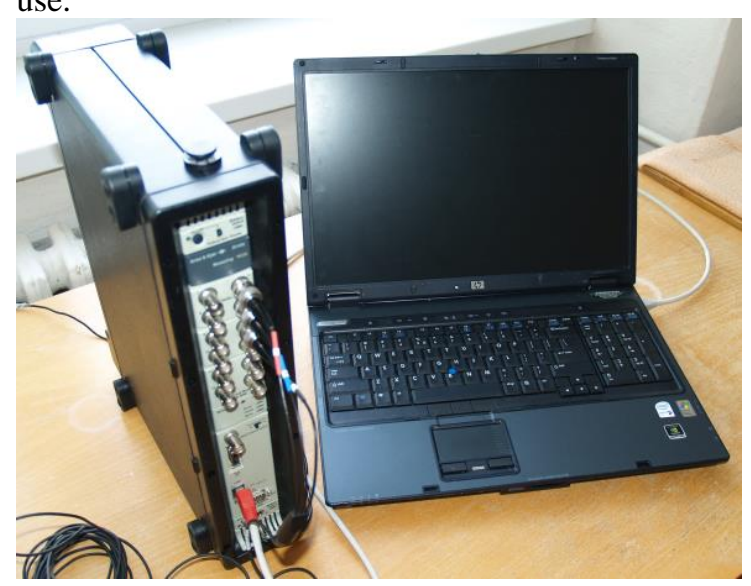

Fig. 7. B\&K PULSE 3560-C vibrodiagnostic hardware

Data recorded by PULSE system was in the form of dependency of vibrations acceleration in axis $\mathrm{X}, \mathrm{Y}$ and $\mathrm{Z}$ on time.

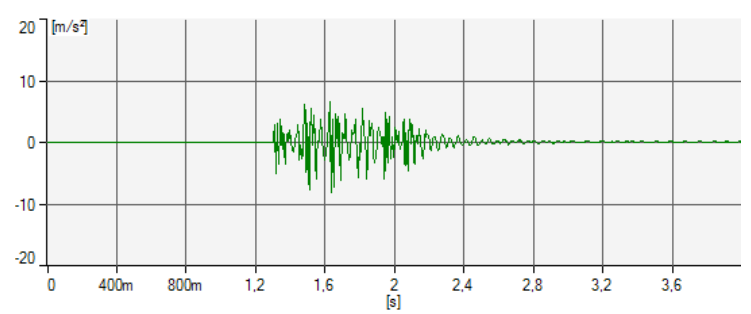

Fig. 8. PULSE time domain output - general example only (not related to the issues discussed below)

Next, this time dependency was transformed to the frequency domain. The method of transform the time domain data into the frequency domain is the Fourier transform [11].

$$
F(\omega)=\int_{-\infty}^{+\infty} f(t) e^{-i \omega t} d t
$$

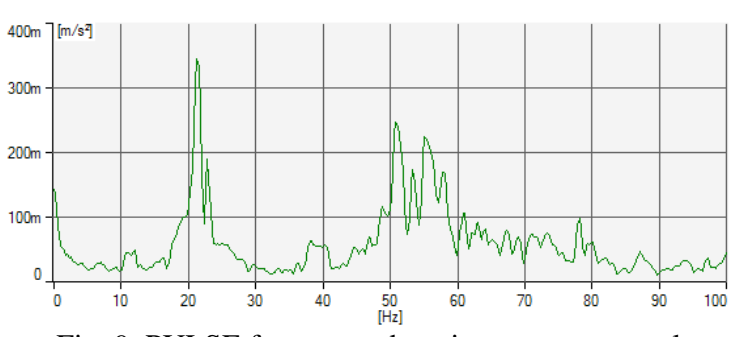

Fig. 9. PULSE frequency domain output - general example only (not related to the issues discussed below)

Fourier transform can be described as $\mathrm{f}(\mathrm{t}) \rightarrow$ $F(\omega)$, or $F(\omega)=\boldsymbol{F}[\mathrm{f}(\mathrm{t})]$, where $\boldsymbol{F}$ is operator of Fourier transform. If $\mathrm{f}(\mathrm{t})$ is meant as a signal (input data), then $F(\omega)$ is spectrum of this input signal. If signal is not continuous, we can use so-called discrete Fourier transform (DFT) [12].

The implementation of the DFT algorithm by a computer system is known as Fast Fourier Transform (FFT).

\subsection{Setting the frequency range of pulse system}

Dynamic balancing of the propulsion unit is a process which results in the minimization of vibrations produced by the operation of the submersible unit. One of the possibilities how to dynamically balance [9][10][13] the rotating system is the following experimental procedure - by changing the distribution of the mass of rotating parts with respect to the axis of rotation, to monitor the level of vibrations. And consequently, ensure a distribution of the mass of the rotating parts that produces minimal vibrations.

T-copter uses electric motors with $\mathrm{Kv}=750$ rpm, which for the used LiPol battery with a nominal voltage of $11.1 \mathrm{~V}$ represents the speed:

$$
750 * 11.1=8325 \mathrm{rpm}
$$

Hovering of the T-copter is possible at $60 \%$ power, at speed:

$$
8325 * 0.6=4995 \mathrm{rpm}
$$

For hovering mode, speed of $4995 \mathrm{rpm}$ represents rotating frequency

$$
f=\frac{4995}{60}=83,25 \mathrm{~Hz}=1 X
$$

If we want to capture a range of frequencies up to $10 \mathrm{X}$, then the vibrodiagnostic hardware must be able to measure the range $0-832.5 \mathrm{~Hz}$. Our PULSE system allows such setting of operating parameters that we were able to perform measurements with a range of $0-800 \mathrm{~Hz}$ (just below the limit of 10X).

\section{PROCESSING OF MEASURED DATA}

Evaluation method of vibrations level is based on calculation of area under the curve $F(\omega)$. By 
another words - the greater vibrations are equal to the larger area bounded by the curve $F(\omega)$.

Area under $F(\omega)$ is defined by integral:

$$
S=\int_{0}^{\omega} F(\omega) d \omega=\int_{0}^{800} F(\omega) d \omega
$$

$S$ value was obtained by simple calculation in MATLAB/Simulink schema.

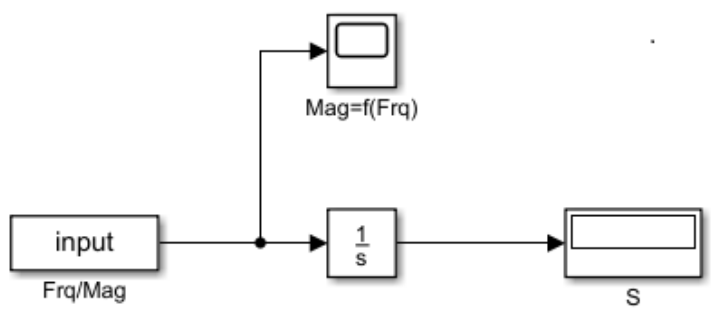

Fig. 10. Calculating of area under the curve $F(\omega)$

SumS is then sum of areas:

$$
\text { SumS }=S(X)+S(Y)+S(Z)
$$

under the curve $F(\omega)$ in $X$ axis $=S(X)$ under the curve $F(\omega)$ in $Y$ axis $=S(Y)$ under the curve $F(\omega)$ in $Z$ axis $=S(Z)$

Measured results are shown in Table 1.

Markings PropPos (A-B-C) represents propellers position for engine 1,2 and 3 - where $A$ is propeller position for engine $1, \mathrm{~B}$ is propeller position for engine 2 and $\mathrm{C}$ is propeller position for engine 3 .

Tab. 1 Measured results of vibrations

\begin{tabular}{|c|c|c|c|c|}
\hline PropPos & $S(X)$ & $S(Y)$ & $S(Z)$ & Sums \\
\hline $45-0-90$ & 169,3 & 13,82 & 73,95 & 257,07 \\
\hline $45-0-135$ & 107,2 & 10,96 & 50,64 & 168,8 \\
\hline $45-45-0$ & 154 & 18,93 & 61,3 & 234,23 \\
\hline $45-45-45$ & 111,9 & 19,3 & 75,6 & 206,8 \\
\hline $45-45-90$ & 147,5 & 14,9 & 53,16 & 215,56 \\
\hline $45-45-135$ & 79,78 & 8,739 & 40,66 & 129,179 \\
\hline $45-90-0$ & 133,3 & 17,41 & 47,85 & 198,56 \\
\hline $45-90-45$ & 94,52 & 12,57 & 46,68 & 153,77 \\
\hline $45-90-90$ & 113,3 & 15,7 & 59,82 & 188,82 \\
\hline $45-90-135$ & 211,4 & 10,45 & 54,91 & 276,76 \\
\hline $45-135-0$ & 127,2 & 19,92 & 53,02 & 200,14 \\
\hline $45-135-45$ & 89,81 & 13,63 & 41,14 & 144,58 \\
\hline $45-135-90$ & 130,8 & 14,89 & 74,96 & 220,65 \\
\hline $45-135-135$ & 93,41 & 8,808 & 50,57 & 152,788 \\
\hline $90-0-0$ & 373,5 & 20,21 & 99,47 & 493,18 \\
\hline $90-0-45$ & 179,2 & 22,04 & 87,8 & 289,04 \\
\hline $90-0-90$ & 257,4 & 15,37 & 93,23 & 366 \\
\hline $90-0-135$ & 274,4 & 18,51 & 87,23 & 380,14 \\
\hline $90-45-0$ & 572,8 & 26,24 & 109,8 & 708,84 \\
\hline $90-45-45$ & 195,6 & 21,58 & 93,43 & 310,61 \\
\hline $90-45-90$ & 384 & 24,19 & 81,84 & 490,03 \\
\hline $90-45-135$ & 249,8 & 13,33 & 85,62 & 348,75 \\
\hline $90-90-0$ & 223,8 & 21,03 & 70,83 & 315,66 \\
\hline $90-90-45$ & 198 & 15,71 & 75,8 & 289,51 \\
\hline $90-90-90$ & 384 & 20,23 & 109,9 & 514,13 \\
\hline $90-90-135$ & 369,1 & 13,97 & 77,38 & 460,45 \\
\hline $90-135-0$ & 383,9 & 27,4 & 106,8 & 518,1 \\
\hline $90-135-45$ & 177,9 & 15,33 & 65,15 & 258,38 \\
\hline $90-135-90$ & 411,8 & 20,73 & 112 & 544,53 \\
\hline $90-135-135$ & 266,4 & 14,93 & 75,56 & 356,89 \\
\hline $135-0-0$ & 647,2 & 23,44 & 123,7 & 794,34 \\
\hline $135-0-45$ & 273,5 & 23,05 & 108,8 & 405,35 \\
\hline $135-0-90$ & 709 & 41,39 & 121,6 & 871,99 \\
\hline $135-0-135$ & 787,7 & 26,93 & 167,5 & 982,13 \\
\hline $135-45-0$ & 869,9 & 34,05 & 168,9 & 1072,85 \\
\hline $135-45-45$ & 320,5 & 29,25 & 139,3 & 489,05 \\
\hline $135-45-90$ & 504 & 28,59 & 125,5 & 658,09 \\
\hline $135-45-135$ & 599,6 & 17,91 & 100,1 & 717,61 \\
\hline $135-90-0$ & 320,8 & 22,69 & 90,89 & 434,38 \\
\hline $135-90-45$ & 298,2 & 19,39 & 91,4 & 408,99 \\
\hline $135-90-90$ & 800 & 29,04 & 161,7 & 990,74 \\
\hline $135-90-135$ & 567,1 & 17,85 & 95,94 & 680,89 \\
\hline $135-135-0$ & 763,6 & 36,6 & 189,2 & 989,4 \\
\hline $135-135-45$ & 621 & 24,87 & 134,9 & 780,77 \\
\hline $135-135-90$ & 483,2 & 20,94 & 113 & 617,14 \\
\hline $135-135-135$ & 886,9 & 29,59 & 186,5 & 1102,99 \\
\hline
\end{tabular}

\begin{tabular}{|c|c|c|c|c|}
\hline PropPos & $\mathbf{S}(\mathbf{X})$ & $\mathbf{S}(\mathbf{Y})$ & $\mathbf{S}(\mathbf{Z})$ & SumS \\
\hline $0-0-0$ & 476,4 & 23,12 & 123,3 & 622,82 \\
\hline $0-0-45$ & 210,9 & 19,02 & 75,73 & 305,65 \\
\hline $0-0-90$ & 110,6 & 14,97 & 58,35 & 183,92 \\
\hline $0-0-135$ & 221 & 12,39 & 83,67 & 317,06 \\
\hline $0-45-0$ & 182,7 & 18,48 & 57,52 & 258,7 \\
\hline $0-45-45$ & 137,9 & 19,67 & 78,6 & 236,17 \\
\hline $0-45-90$ & 497,5 & 30,79 & 94,17 & 622,46 \\
\hline $0-45-135$ & 238,8 & 15,77 & 97,24 & 351,81 \\
\hline $0-90-0$ & 325,3 & 26,48 & 102,7 & 454,48 \\
\hline $0-90-45$ & 147,4 & 17,17 & 63,54 & 228,11 \\
\hline $0-90-90$ & 161,1 & 17,21 & 74,48 & 252,79 \\
\hline $0-90-135$ & 330,2 & 13,96 & 74,92 & 419,08 \\
\hline $0-135-0$ & 179,3 & 18,99 & 66,6 & 264,89 \\
\hline $0-135-45$ & 124,5 & 16,01 & 50,01 & 190,52 \\
\hline $0-135-90$ & 344,6 & 18,03 & 108,5 & 471,13 \\
\hline $0-135-135$ & 524,2 & 21,15 & 145 & 690,35 \\
\hline $45-0-0$ & 138,3 & 16,73 & 54,86 & 209,89 \\
\hline $45-0-45$ & 110,9 & 19,4 & 62,56 & 192,86 \\
\hline & & & & \\
\hline
\end{tabular}


Optimal position of propellers (producing a minimal level of vibrations in the experimental $\mathrm{T}$ copter's center of gravity) is determined by formula:

$$
S_{r}=\min (\operatorname{SumS})
$$

The data in the Tab. 1 shows following:

- minimal vibrations (defined by $S_{\mathrm{r}}=129.179$ ) is at propeller position 45-45-135 (green line in Table 1).

- highest level of vibrations (defined by $\mathrm{S}_{\mathrm{r}}=$ 1102.99) represents propeller position 135-135135 (red line in Table 1).

The next figures shows frequency spectrum of vibrations for the best and worst propellers position in $\mathrm{X}, \mathrm{Y}$ and $\mathrm{Z}$ axes.

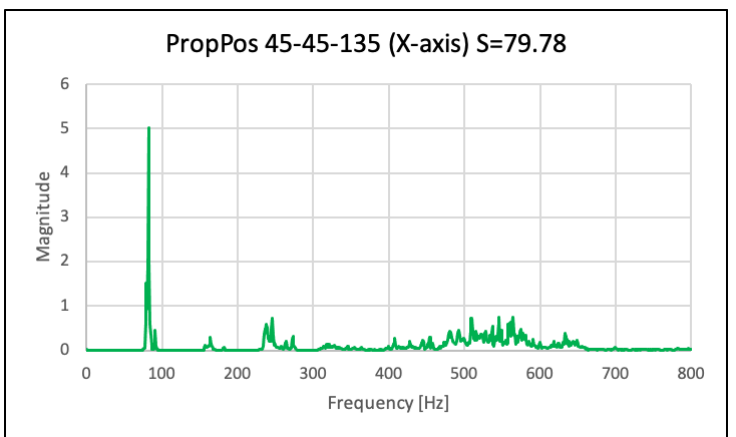

Fig. 11. Frequency spectrum of vibration in $\mathrm{X}$-axis the best propellers position

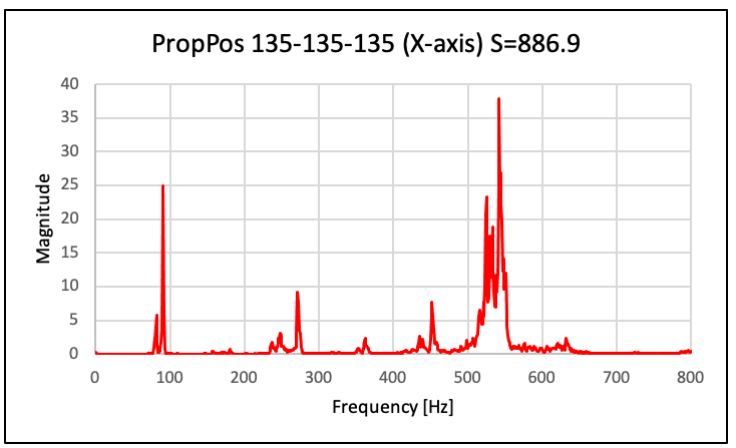

Fig. 12. Frequency spectrum of vibration in $\mathrm{X}$-axis the worst propellers position

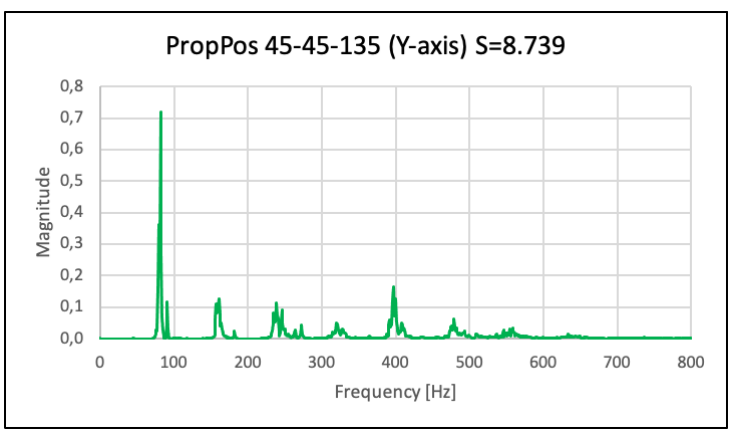

Fig. 13. Frequency spectrum of vibration in Y-axis the best propellers position

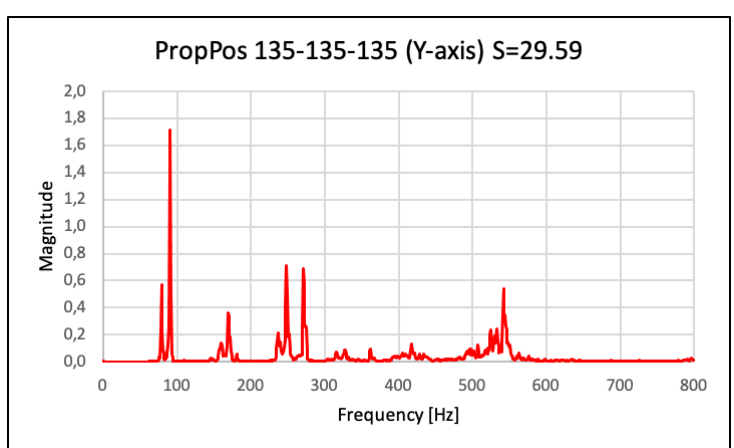

Fig. 14. Frequency spectrum of vibration in Y-axis the worst propellers position

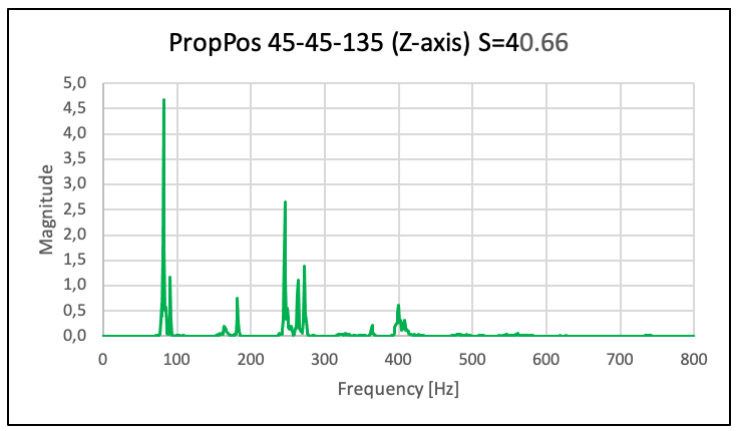

Fig. 15. Frequency spectrum of vibration in Z-axis the best propellers position

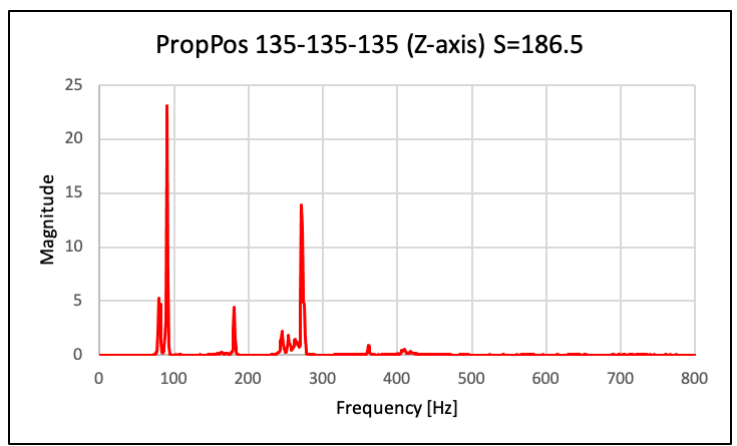

Fig. 16. Frequency spectrum of vibration in Z-axis the worst propellers position

\section{CONCLUSION}

The present paper demonstrates a method of minimizing the vibration load of a multicopter based on dynamic balancing of power units. Our experiment was designed, so that the measurements were performed only in the mode of hovering of the multicopter, so that we measured only the effect of vibrations from the propulsion units and so that the measurements are not degraded by additional vibrations that occur due to horizontal or vertical movement of the multicopter. Therefore, the results we obtained cannot be completely generalized to out of hovering flight mode. This method represents objective way how initially to setup of multicopter, not only based on feeling.

\section{REFERENCES}

1. Bottega, J. William. Engineering Vibrations. Boca Raton: Taylor \& Francis Group, LLC. 2006. 
2. Kelly S. Graham. Schaum's outline of theory and problems of mechanical vibrations. USA: The McGraw-Hill Companies, Inc. 1996.

3. Myklestad O. Nils. Fundamentals of vibration analysis. Dover Publications. 2018.

4. Kelly S. Graham. Mechanical Vibrations: Theory and Applications, Cengage Learnin. 2012.

5. Belal H. Sababha, Hamzeh M. Al Zu'bi, Osamah A. Rawashdeh. A rotor-tilt-free tricopter UAV: design, modelling, and stability control. Int. J. Mechatronics and Automation. 2015;5(2-3). https://doi.org/10.1504/IJMA.2015.075956

6. Mahony R, Kumar V, Corke P. Multirotor aerial vehicles. IEEE Robotics and Automation Magazine. 2012;19(3):20-32. https://doi.org/10.1109/MRA.2012.2206474.

7. Mac Camhaoil M. Static and dynamic balancing of rigid rotors. Bruel\&Kjaer application notes BO 027612. 2016:1-20.

8. Norfield, D. Practical balancing of rotating machinery. Oxford: Elsevier. 2006.

9. Wilcocx E. Vibration analysis in turbomachinery. 45th Turbomachinery \& 32nd Pump Symposia, Houston, Texas. 2016.

10. Adams L. Maurice. Rotating machinery vibration. Case Western Reserve University. Cleveland, Ohio. 2001.

11. Kammler D. A first course in fourier analysis. Cambridge University Press, New York. 2007.

12. Chu Eleanor. Discrete and continuous fourier transforms analysis. Applications and Fast Algorithms. Taylor\&Francis. 2019.

13. Vance J, Zeidan F, Murphy B. Machinery vibration and rotordynamics. Hoboken: John Wiley and Sons. 2010 .

Received 2021-05-19

Accepted 2021-08-16

Available online 2021-08-19

Vladimír POPARDOVSKÝ, Eng., Ph.D. works at the Department of Mechanical Engineering, Armed Forces Academy in Liptovský Mikuláš. He received his engineer degree from the Faculty of Chemical Technology, Slovak Technical University in Bratislava in 1994. He received a Ph.D. degree from the Faculty of Electrical Engineering and Information Technology, Slovak Technical University in Bratislava in 2000. His research interest is advanced automatic control of mechanical systems.

Lukáš NOVOTNÝ Eng. is the Ph.D. student at the Department of Mechanical Engineering, Armed Forces Academy in Liptovský Mikuláš. He received his engineer degree in 2017 in Armament and technics of military forces from Department of Mechanical Engineering, Armed Forces Academy in Liptovský Mikuláš. His research area is fuel cell technology in military applications.

Marek FERENČÁK, Tomáš KRIŠ, Miroslav TOMAŠTíK are students at the Department of Mechanical Engineering, Armed Forces Academy in Liptovský Mikuláš. 